\title{
Client's immersed and distanced speech and therapist's interventions in emotion-focused therapy for depression: an intensive analysis of a case study
}

\author{
Ana Bela Couto, ${ }^{1,2}$ Eunice Barbosa, ${ }^{3}$ Sara Silva, ${ }^{1,2}$ Tiago Bento, ${ }^{1,2}$ Ana Sofia Teixeira, ${ }^{4}$ João Salgado, ${ }^{1,2}$ Carla Cunha ${ }^{1,2}$ \\ ${ }^{1}$ Center of Psychology, University of Porto, Porto; ${ }^{2}$ Department of Psychology and Communication, University Institute of Maia-ISMAI, \\ Maia; ${ }^{3}$ Cognitive-Behavioural Research Centre, Department of Psychology, University of Coimbra, Coimbra; ${ }^{4}$ Research Center on \\ Psychology, Department of Psychology, University of Minho, Braga, Portugal
}

Correspondence: Carla Alexandra Castro Cunha, University Institute of Maia-ISMAI, Avenida Carlos Oliveira Campos, Castêlo da Maia, 4475-690 Avioso S. Pedro, Portugal.

Tel: +351.229 .866000 - Fax: +351.808202214 .

E-mail: ccunha@ismai.pt

Citation: Couto, A.B., Barbosa, E., Silva, S., Bento, T., Teixeira, A.S., Salgado, J., \& Cunha, C. (2016). Client's immersed and distanced speech and therapist's interventions in emotion-focused therapy for depression: an intensive analysis of a case study. Research in Psychotherapy: Psychopathology, Process and Outcome, 19(2), 136-149. doi: 10.4081/ripppo.2016.205

Contributions: the sample was provided by the head research JS, which is the therapist of the clinical case analysed. Coding process was performed by $\mathrm{ABC}, \mathrm{EB}$ and $\mathrm{AST}$. The data analysis was performed by $\mathrm{ABC}, \mathrm{EB}, \mathrm{CC}$ and TB (State Space Grids' analysis). The writing of the manuscript was performed by $\mathrm{ABC}$ and $\mathrm{SS}$, with all the reviews performed by $\mathrm{CC}$ and $\mathrm{EB}$ (client's immersed and distanced speech revisions)

Conflict of interest: the authors declare no potential conflict of interest.

Funding: this article was supported by the Foundation for Science and Technology (FCT; Lisboa, Portugal) by the funded project PTDC/PSI-PCL/103432/2008 and by doctoral individual grant (SFRH/BD/77183/2011).

Conference presentation: this research was presented at national and international conferences. Communications: i) IX Congresso Iberoamericano de Psicologia $/ 2^{\circ}$ Congresso da OPP, Lisboa, Portugal (2014); ii) VIII Simpósio Nacional de Investigação em Psicologia, Aveiro, Portugal (2013). Poster: i) $45^{\text {th }}$ Annual Meeting of Society for Psychotherapy Research, Copenhagen, Denmark (2014); ii) VI Congreso Internacional y XI Nacional de Psicología Clínica, Santiago de Compostela, Spain (2013).

Received for publication: 2 November 2015.

Revision received: 10 April 2016.

Accepted for publication: 4 August 2016.

This work is licensed under a Creative Commons Attribution NonCommercial 4.0 License (CC BY-NC 4.0).

CCopyright A.B. Couto et al., 2016

Licensee PAGEPress, Italy

Research in Psychotherapy:

Psychopathology, Process and Outcome 2016; 19:136-149

doi:10.4081/ripppo.2016.205

\begin{abstract}
Previous laboratory studies have explored the importance of participants adopting an immersed or distanced perspective in the analysis of their experiences. These studies concluded that distancing allows analyzing emotions in a healthier way and immersion leads to higher vulnerability. However, in psychotherapy, the relationship between these perspectives and clinical change has been less investigated. The present study aims to contribute to understanding how these variables evolve during psychotherapy and also to explore the therapist's contributions to this process. This study analyzes a good-outcome case of emotion-focused therapy for depression through two observational measures of psychotherapy process: the measure of immersed and distanced speech - which identifies client's adoption of an immersed or distanced stance when talking about their problems - and the helping skills system - which identifies therapist's interventions focused on exploration, insight or action. Results showed a decrease of immersed speech and an increase of distanced speech along the process, with a higher frequency of exploration skills preceding both types of client's speech. Finally, the evolution of therapist's and client's speech showed a reasonable flexibility of therapeutic dialogue throughout the sessions, in particular due to the evolution of client variables (evidencing a higher diversity of behaviors).
\end{abstract}

Key words: Immersion; Distancing; Therapist's interventions; Emotion-focused therapy; Depression.

\section{Introduction}

In psychotherapy, the variables related to therapeutic communication have earned a strong emphasis and empirical support (Bickman, 2008). According to Salvatore and Tschacher (2012), we can see the temporal dependency of the therapeutic process through a semantic communication level, since the meaning of any event in the dyadic communication does not end in the event itself. Inversely, as psychotherapy is a dynamic process, what happens now is a consequence of what happened before, and a starting point to what will happen next (Salvatore \& Tschacher, 2012). In this sense, the therapeutic process can be seen as a resource to help people change problematic patterns of thought or interaction that occur in an interdynamic system. More specifically, therapist and client contribute to- 
gether to the moment-by-moment dynamics of their interaction and develop strategies to unsettle this system (Trop, Burke, \& Trop, 2013). In this way, the dyadic therapeutic relationship can be seen as a non-constant process across psychotherapy since both elements of the dyad work as a dynamic system that may have different impacts in different moments (Salvatore \& Tschacher, 2012). Therefore, it is supposed that across this process there will be a diversification of therapist's interactions (e.g. therapist's interventions) and client changes (e.g. client's immersed and distancing perspectives adopted in discourse) (Town, Hardy, Mccullough, \& Stride, 2012). To investigate how therapist's interventions and client's discourse perspectives evolve throughout a single case of emotion-focused therapy (EFT) for depression, the present study will explore the interaction between these variables through a state space grids (SSG) analysis (Lewis, Zimmerman, Hollenstein \& Lamey, 2004).

\section{Immersion and distancing: a definition of concepts and a brief review of clinical implications}

When a person is disclosing a difficult or problematic experience that is lived in the present, two perspectives can be adopted in the analysis of one's own personal experience: an immersed or a distanced perspective. In an immersed perspective, the experience is analyzed in the first person; that is, original thoughts, feelings, behaviors and events experienced repeat themselves (Nigro \& Neisser, 1983). In contrast, in a distanced perspective, personal experience is analyzed adopting a third person stance; that is, as an observer who is able to recognize patterns or new aspects. Some authors use the following expressions: seeing the experience through his/her own eyes (Ayduk \& Kross, 2010b, p. 810), to refer to an immersed stance and, in turn, seeing the experience as a fly on the wall to refer to a distanced, observer stance (Ayduk \& Kross, 2010b, p. 809).

According to previous laboratory and experimental studies under this approach, when immersed, people tend to reflect on problematic experiences on a more concrete way, recounting specificities and characteristics of the experience in a more passive way. This can lead or intensify negative affect (I was robbed this week and I felt very scared. They took me my house key and I need to switch the lock immediately). In contrast, when distanced, people tend to reflect on problematic experiences in a more abstract way, creating new meanings and more positive emotional states (I concluded that I cannot punish myself for things that I cannot change) (Ayduk \& Kross, 2010a, 2010b; Kross, Ayduk, \& Mischel, 2005).

Previous laboratory and clinical studies by authors such as Ayduk and Kross (e.g. Ayduk \& Kross, 2010a, 2010b; Kross, 2009; Kross \& Ayduk, 2008, 2011; Kross et al., 2005) have shown that adopting a distancing stance has been associated with more positive outcomes, such as: i) better reconstruction of clinical problems; ii) lower ruminative processes; iii) decrease of depressive symptoms; and iv) the promotion of individual well-being.

The previous laboratory studies, led these authors (Ayduk \& Kross, 2010a, 2010b; Kross \& Ayduk, 2009, 2011; Kross et al., 2005) to conclude that an increased distancing stance allows analyzing personal experiences more adaptively, generating more positive emotions and thus contributing to a reconstruction of their meanings and to a more adaptive reflection. On the other hand, in the case of higher immersed stance, the person will be more vulnerable to rumination as a result of a greater focus on retelling the experience and confronting negative, painful experiences (Kross \& Ayduk, 2009; Kross et al., 2005). Rumination, as defined by Nolen-Hoeksema (1991), refers to behaviors and thoughts that focus one's attention on one's depressive symptoms and on the implications of these symptoms ( $\mathrm{p}$. 569). Going further in the attempt to explore the link between these perspectives and clinical symptoms, Kross and Ayduk (2008) also analyzed feelings associated with an experience of depression. In this study, they found that a more distanced perspective upon problematic experiences allows less emotional reactivity, comparing to the analysis from an immersed perspective.

Despite the relevance of the studies carried out by Kross and Ayduk (2011) denoting that distancing may be a beneficial process for the reconstruction of meaning related to the negative experiences of more vulnerable populations (e.g. depressed participants), up until now, few studies have explored the evolution of immersed and distanced perspectives along psychotherapy. The present study attempts to address this issue, aiming to contribute to the understanding of how immersed and distanced perspectives evolve in other clinical contexts, such as psychotherapy, beyond laboratory, experimental studies.

\section{Immersion and distancing in psychotherapy}

Along this line of reasoning, previous studies within our research team have applied the study of immersion and distancing in psychotherapy (Barbosa, Bento, Amendoeira, Mendes, Gouveia, Salgado, 2012; Barbosa et al., 2013; Barbosa, Salgado et al., 2012). For that, a measure of immersed and distanced speech (MIDS) was developed, based on the research by Kross and collaborators (2005), to code how immersed or distanced the client is in his/her perspective along each statement during the therapeutic conversation (more on this measure below, on the method section).

A previous study using the MIDS conducted with a good-outcome case of cognitive behavioral therapy (CBT) with a depressed participant, analyzed the evolution of the immersion and distancing processes and explored its relation with the evolution of clinical symptoms, during the therapeutic process (Barbosa, Bento et al., 2012). Preliminary results revealed a decrease in the immersed speech and an increase in the distancing speech during the therapeutic process (Barbosa, Bento et al., 2012). At a first 
glance, the findings seem to match the results of laboratory studies. However, other results were not as consistent with the argument by Ayduk and Kross (2010a, 2010b), Kross and Ayduk (2008, 2009, 2011), Kross et al. (2005): namely, psychotherapy process was mainly characterized by an immersed perspective, even though clinical symptoms were diminishing. This case pretended another interesting finding related with emotional arousal of negative emotions: from the middle phase there was a transformation of emotional arousal, passing from negative to positive emotions. Yet, the client was still mainly adopting an immersed stance (changes in the predominance of a distanced over an immersed stance only occurred at a final phase of therapy). In this sense, Barbosa, Bento and collaborators (2012) concluded that it seems important to reduce immersion and increase distancing along the therapeutic process, as expected. Furthermore, their findings suggest that this movement is important for client well being and improving therapeutic outcome. However, a predominance of an immersed stance was not impeditive of a decrease of symptomatology. Therefore, these authors argue against immersion being considered as harmful to the therapeutic process (contrary to the claims by Ayduk \& Kross, 2010a, 2010b; Kross \& Ayduk, 2008, 2009, 2011; Kross et al., 2005). However, given the exploratory nature of the previous studies, further efforts need to be conducted to improve understanding of the role of immersion and distancing in psychotherapy.

\section{The present study: therapist's interventions and client's immersed and distanced speech in emotion-focused therapy}

The present study attempts to contribute to address two specific gaps on the current literature on immersion and distancing. The first contribution builds on the previous work on immersion and distancing in psychotherapy, by Barbosa, Bento and collaborators (2012). While Barbosa, Bento and collaborators (2012) studied a case of CBT, in the present study, we will focus on another therapeutic modality: EFT. As proposed by Greenberg, Elliott and colleagues (cf. Elliott, Watson, Goldman, \& Greenberg, 2004; Greenberg, 2006; Greenberg, Rice, \& Elliott, 1993; Greenberg \& Watson, 2006), EFT assumes that enduring change happens by having clients focus on their core, maladaptive painful experiences and unmet needs. According to this view, when the therapeutic context facilitates an increased access, regulation and reflection upon core, maladaptive emotions, emotion transformation is promoted by having clients experience new, more adaptive alternatives (Elliott et al., 2004; Greenberg \& Watson, 2006). Thus, we consider especially compelling to address the role of client immersion and distancing in a good outcome case of this experiential model, since EFT assumes that change derives from having clients focus on painful issues and explore problematic experiences throughout therapy (Greenberg, 2006). Therefore, client immersion might have a more prominent role in this therapy modality than in others, such as CBT (Barbosa, Bento et al., 2012). Furthermore, studying EFT may contribute further to the discussion around the potential or harmful effects of an immersed stance on personal problems (cf. Ayduk \& Kross, 2010a, 2010b; Kross \& Ayduk, 2008, 2009, 2011; Kross et al., 2005).

The second contribution of the present study addresses therapist's contributions to client change in immersion and distancing. Previous studies looking at changes on client immersion and distancing in psychotherapy have not yet addressed therapist's contributions. Nevertheless, therapist variables have gained an increasingly strong emphasis in the last decades. A special focus has been given to the therapist's role and the relationship between therapeutic process and clinical outcome (Nuovo, 2011), as well as conversation patterns between therapists and clients (Bucci, 2013; Dagnino, Krause, Pérez, Valdés, \& Tomicic, 2012). We consider that this line of research has important implications, namely to the training of undergraduate students (Nuovo, 2011) in the use of these techniques (Chui et al., 2014; Hill et al., 2015; Hill, Spangler, Chui, \& Jackson, 2014; Hill, Spangler, Jackson, \& Chui, 2014; Jackson et al., 2014; Meystre et al., 2014; Spangler et al., 2014) due to the effectiveness of these on therapeutic outcome across different modalities of psychotherapy (Cunha et al., 2012; Goates-Jones, 2004; Goates-Jones, Hill, Stahl, \& Doscheck, 2009; Hill et al., 2015).

A specific system chosen in this study to evaluate therapist's interventions is the helping skills system (HSS; Hill, 2002, 2014), which remains one of the most wellknown and widely used until now (cf. Chui et al., 2014; Goates-Jones, 2004; Goates-Jones et al., 2009; Hill, 2005; Hill et al., 2015; Hill, Spangler, Chui, \& Jackson, 2014; Hill, Spangler, Jackson et al., 2014; Jackson et al., 2014; Meystre et al., 2014; Spangler et al., 2014). The HSS codes several types of therapist interventions, organized around three major categories: i) exploration skills (related to an exploration phase of psychotherapy, aim to deepen the exploration of client problems, through the use of approval and reassurance, closed questions, open questions, restatements and reflections of feelings); ii) insight skills (related to an insight phase of psychotherapy, aim to facilitate increased client insight regarding difficulties, through the use of challenges, interpretations, disclosures and immediacy); and iii) action skills (related to an action phase of psychotherapy, aim to help clients transform their lives through new actions or behaviors, through information and direct guidance - Hill, 2014).

A recent study looking at therapist's interventions (through the HSS) in EFT in depression conducted by Cunha and collaborators (2012) focused on how different skills were related to client narrative change in good and poor outcome cases (more specifically, innovative moments appearing in client speech). Results indicated that exploration skills were more frequent than other skills 
across all different therapy phases of good and poor-outcome cases. Action and insight skills, although they were less frequent, occurred more often in poor-outcome cases than in good-outcome cases (Cunha et al., 2012). Yet, whereas Cunha and collaborators (2012), focused on client narrative change (through the presence of innovative moments in client speech), the present study looks specifically to the perspectives adopted in client speech i.e. an immersed or a distancing stance - and to how these evolve in an EFT dyad.

In sum, in the present study we will: i) describe the evolution of client's immersed and distanced speech in a good outcome case of EFT; ii) identify which therapist interventions precede each types of speech; and, iii) characterize the evolution of the dyadic interaction (therapist-client) in function of these processes. Based on these goals and on the literature reviewed above, we raise the following hypotheses: i) a decrease of immersion and an increase of distancing along the therapeutic process, with a higher prevalence of immersion in the initial stage; ii) a higher prevalence of exploration skills throughout the process, with a slight evolution of insight and action skills along the therapeutic process; iii) a flexible dyadic pattern throughout the process, with a stable evolution of some attractors, namely exploration with immersion in the initially and middle phase, and exploration with distancing in final stage.

\section{Materials and Methods}

\section{Sample and selection of participants \\ Client}

Julia (fictional name) was a 30-year-old, single and unemployed, white woman when she participated in the research project. This project was a randomized clinical study that contrasted CBT with EFT conditions for the treatment of mild to moderate depression (without pharmacotherapy).

Julia had a diagnosis of major depressive disorder, mild (American Psychiatric Association, 2006) assessed at intake through the structured clinical interview for DSM-IV disorders - Axis I (SCID-I; First, Spitzer, Gibbon, \& Williams, 1997) and Axis II (SCID-II; First, Gibbon, Williams, \& Benjamin, 1997). She met the inclusion criteria for the study, specifically: she was diagnosed with major depressive disorder (mild or moderate), was not taking psychotropic medication, and exhibited a global functional evaluation superior than 50 . The clinical problems identified for this participant were her feelings of insecurity and inadequacy, and the rejection and negligence of her dysfunctional family. The evolution of global clinical symptoms and depressive symptoms, measured by the Outcome Questionnaire-45.2 (OQ-45) [Lambert (2012); Portuguese version by Machado and Fassnacht (2014)] and Beck Depression Inventory-II (BDI-II) [Steer,
Ball, Ranieri, and Beck (1999); Portuguese version by Coelho, Martins, and Barros (2002)] respectively, throughout five sessions of the therapeutic process (namely, session 1, 4, 8, 12 and 16) can be observed in Table 1. In order to check if Julia presented a reliable and clinically significant change, a reliable change index (RCI) criteria was calculated for BDI-II and OQ-45, according to the guidelines by Jacobson and colleagues (Jacobson \& Truax, 1991; McGlinchey, Atkins, \& Jacobson, 2002). Julia decreased from a score of 19 to 2 in the BDIII (below the cutoff point of 14.29 and a change higher than 8.46 from pre to post-test $-\mathrm{RCI}=2.95$; Seggar, Lambert, \& Hansen, 2002) in depressive symptoms and from a score of 82 to 59 in the OQ-45 (below the cutoff point of 62 and a with a higher decreased than 15 from pre to post-test $-\mathrm{RCI}=2.49$; Machado \& Fassnacht, 2014) in clinical symptoms. As both RCIs are higher than 1.96 (Jacobson, \& Truax, 1991), Julia was considered a recovered and good-outcome case.

\section{Therapist}

The therapist was a 43-year-old European, white male. He had 20 years of experience as a psychotherapist and 5 years of training and supervision in EFT. He received weekly peer-supervision throughout the study, based on the analysis of video-recorded sessions.

\section{Research team}

A total of three judges, all females in her twenties, participated in this study as judges: two were PhD students in clinical psychology and one a graduate student in clinical psychology. One of the judges was aware of the outcome status of this case; the other two were blind to it.

\section{Treatment}

Sessions of the Julia case were based on the EFT manuals for depression (Elliott et al., 2004; Greenberg \& Watson, 2006), which aim to access and restructure maladaptive emotional responses, as well as enable and validate the emergence of new emotions that facilitate emotional change and self-reorganization (Greenberg \& Pascoal-Leone, 2006; Greenberg \& Watson, 2006). EFT combines the empathic, client-centered relationship from humanistic therapies, and the more directive, experiential techniques from gestalt therapy and focusing-oriented

Table 1. Evolution of clinical symptoms.

\begin{tabular}{lcccccc}
\hline Measures & Pre-test & $\mathbf{1}$ & $\mathbf{4}$ & $\begin{array}{c}\text { Session } \\
\mathbf{8}\end{array}$ & $\mathbf{1 2}$ & $\mathbf{1 6}$ \\
\hline BDI-II & 19 & 11 & 15 & 18 & 8 & 2 \\
\hline OQ-45.2 & 82 & 77 & 75 & 72 & 72 & 59 \\
\hline
\end{tabular}

BDI-II, Beck Depression Inventory-II; OQ-45.2, Outcome Questionnaire 45.2. 
psychotherapy (Gendlin, 1996; Greenberg, 2002). EFT is marker-guided psychotherapy, since it evolves through specific tasks that match and are implemented when clients present specific problem markers (Elliott et al., 2004; Greenberg, 2002, 2010; Greenberg \& Watson, 2006; Pos \& Greenberg, 2007). Some examples are: i) two-chair work for conflict splits; ii) empty-chair work for unfinished business; iii) evocative enfolding for problematic reactions; iv) focusing for unclear felt sense.

\section{Measures}

\section{Outcome measures}

In order to monitor clinical symptoms, the present study used the following measures applied in sessions 1 , 4, 8, 12 and 16:

Beck Depression Inventory - II (BDI-II) [Steer et al. (1999); Portuguese version by Coelho et al. (2002)]. The BDI-II is a 21-item self-report measure used to characterize the intensity and diversity of depressive symptoms in the two weeks prior to its completion. The instrument has a high internal consistency $(\alpha=.91$; reported by Steer, Brown, Beck, \& Sanderson, 2001), and a cut-off point of 14.29 points with a RCI of 8.46 (Seggar et al., 2002).

Outcome Questionnaire-45.2 (OQ-45.2) [Lambert (2012); Portuguese version by Machado \& Fassnacht (2014)]. The OQ-45.2 is a 45 -item self-report measure, designed to assess global clinical symptoms in the client reported in the previous week to its completion (Lambert, 2012). In the study of psychometric properties of the Portuguese version, the cut-off was defined as 62 , and the $\mathrm{RCI}$ as 15 points. This instrument has evidenced high internal consistency $(\alpha=.93$, reported by Machado \& Fassnacht, 2014).

\section{Measure of immersed and distanced speech}

To code client speech we used is the measure of immersed and distanced speech (MIDS) (a measure adapted from Ayduk \& Kross, 2010a; Barbosa, Bento et al., 2012). This measure focuses on the analysis of client's speech, coding how immersed or distanced clients are in their perspective along each statement during the therapeutic conversation. This measure classifies immersed speech in two nominal and mutually exclusive categories: what statements and attributive statements. These two categories correspond to concrete description of the experience according to an egocentric point of view. However, while what statements are assigned to speech in which clients describe a sequence of events, thoughts or behaviors about $\mathrm{him} /$ herself or others (What happened), attributive statements are assigned to speech in which client describes characteristics that show his/her emotional involvement, feelings or internal states about him/herself or others (How I/others feel/felt). Distancing speech is classified also according to two nominal and mutually exclusive categories: insight statements and closure statements. These categories correspond to an abstract description of the experience as if it was seen by a third person. More specifically, while insight statements are assigned to speech in which clients establish connections between events, behaviors, feelings and cognitions, showing a clearer understanding about the experience; closure statements are assigned to speech in which client expresses the experience in a broader context based on past and current experiences, providing a sense of closure, as, for example reevaluation of the situations. The speech that it is not related to clinical problems or to therapy issues is considered as uncodable. These categories were adapted from previous investigations of Kross and collaborators (2005). The article of the validation of MIDS is under preparation, however, preliminary results show a good internal consistency for both immersion and distancing categories $(\alpha=.95$ and .91 respectively), as well as an interrater agreement that ranged from .75 to .96 (good to strong agreement; Hill \& Lambert, 2004), with a strong agreement between pairs of judges for the entire sample $(\mathrm{K}=.82)$.

\section{Helping skills system}

To code therapist's interventions we used the HSS (Hill, 2002), which remains one of the most well-known and widely used until now (Chui et al., 2014; Cunha et al., 2012; Goates-Jones, 2004; Goates-Jones et al., 2009; Hill, 2005; Hill et al., 2015; Hill, Spangler, Chui, \& Jackson, 2014; Hill, Spangler, Jackson, et al., 2014; Jackson et al., 2014; Meystre et al., 2014; Spangler et al., 2014). The HSS is a revision of the hill counselor verbal response category system (Hill, 1978) and consists in 12 nominal and mutually exclusive categories of therapist's interventions, organized around three major categories, namely exploration, insight and action skills. Exploration skills (related to an exploration phase of psychotherapy, aim to deepen emotional exploration in the client) group approval and reassurance, closed questions, open questions, restatements and reflection of feelings. Insight skills (related to an insight phase of psychotherapy, aim to facilitate increased client insight) group challenges, interpretations, self-disclosures and therapist immediacy. Action skills (related to an action phase of psychotherapy, aim to help clients transform their lives through new actions or behaviors) group information and direct guidance (Hill, 2014). When therapist's statements do not fit in any of these skills, they are coded as Other. In terms of the reliability of this system, Hess, Knox and Hill (2006) reported a strong interrater agreement (Hill \& Lambert, 2004) between pairs of judges $(\mathrm{K}=.91)$.

\section{Procedures}

In this study we analyzed 5 psychotherapy sessions with Julia: sessions 1 and 4 (representing the initial phase of psychotherapy), 8 and 12 (representing the middle phase), and 16 (representing the final phase). These sessions were selected to match the sessions where clinical 
symptoms were monitored (i.e. BDI-II and OQ-45; cf. above). These sessions were initially transcribed according to the rules of Mergenthaler and Stinson (1992) and the qualitative analysis of these sessions took place along the steps described below.

\section{Step 1: unitizing}

For unitizing therapist and client speech, each talking turn was divided into units of grammatical sentences (i.e. every minimal unit with a subject and a verb), based on the procedures described by Hill (2004). This unit consists of an independent or a main clause, which occurs by itself or with more than one dependent or subordinate clauses. Initially, training sessions were performed by the three judges, reaching a satisfactory level of agreement (at least 90\% agreement in unitizing between pairs of judges). Afterwards, judges advanced to the division in units of the five sessions to analyze, reaching a satisfactory agreement for the client $(92.62 \%)$ and therapist (93.7\%) units of analysis. As each talking turn can have more than one unit, the judges subsequently chose, through consensual agreement, which unit of analysis was predominant and would be coded according to the HSS and the MIDS. The criterion used to choose was based on the unit in which the content was responded or used by the other dyadic element in the next talking turn. For example, if therapist says I wonder if we could explore a little more what you have just said. How did you felt in that situation? and client respond I felt stressed, then the predominant unit of therapist talking turn is How did you felt in that situation?

\section{Step 2: coding with the helping skills system}

In the next phase all judges initiated the training in HSS, reaching a satisfactory agreement $(.789$, calculated by Cohen's Kappa). According to Hill and Lambert (2004), an agreement is satisfactory when the Cohen's Kappa is greater than .75. After this, all judges were reliable to proceed to the coding of all therapist units of analysis, classified according to the categories of therapist interventions according to the HSS. The three judges obtained high reliability (Cohen's Kappa $=.854$; according to Hill \& Lambert, 2004). Then, disagreements were resolved by consensus between the three judges.

\section{Step 3: coding with the measure of immersed and distanced speech}

The third phase was initiated through training of judges in the MIDS. According to the application of this measure, all client units of analysis were classified according to the subcategories of immersed or distancing speech, described above. Inter-judge reliability in the MIDS was high (Cohen's Kappa $=.831$; according to Hill $\&$ Lambert, 2004). Disagreements were resolved through consensus between the two judges.

\section{Step 4: qualitative and quantitative analysis of results}

MS Excel was used for the descriptive analysis of the evolution of immersed and distanced speech and of the therapeutic interventions.

To study the evolution of the dynamic system throughout the process and according to the variables under study (types of client speech and therapist interventions), we used the SSG analysis through the Gridware software (Lamey, Hollenstein, Lewis, \& Granic, 2004). The state space grids are a graphical and statistical approach borrowed from the dynamic systems theory and applied to developmental psychology (Lewis, Lamey \& Douglas, 1999). SSG allows the development of hypotheses about dyadic behavioral processes, on a moment-to-moment basis, and also to describe dyadic behavioral patterns that emerge from the interaction within dyad (Provenzi, Borgatti, Menozzi, \& Montirosso, 2015); in this case - between therapist and client. These patterns are depicted graphically in the present study by a $4 \times 3$ grid with two mutually exclusive and synchronized categorical time series (Hollenstein, 2015). Here, the 4 types of client speech (what and attributive statements as categories for client immersed speech, plus insight and closure statements as categories for client distancing speech) are represented in the $y$-axis, and the 3 types of therapist interventions in the $\mathrm{x}$-axis (exploration, insight and action interventions according to the HSS). We constructed 5 different grids to represent sessions $1,4,8,12$ and 16 , each one with 12 cells ( $4 \times 3$ categories).

These grids show all possible states or behaviors occurring in the dyad in a given time frame (Hollenstein, 2007, 2015). In our study, each grid represents the dyadic exchanges occurring in a given session, by showing the shift between therapist interventions and client speech categories (immersed or distanced). Each cell represents a simultaneous interception of dyadic behaviors, and each circle (placed inside the cell) represents an interaction between therapist and client categories, i.e., a circle represents a given, therapist interventions followed by a specific client speech category. Additionally, as a SSG allows representing the temporal evolution of the dyadic exchange, each line and arrow between circles (and cells) depicts the trajectory and the succession of exchanges, given the direction from one interaction to another. Finally, the hollow circle represents the first behavior occurrence in the session (Granic \& Hollenstein, 2003; Hollenstein, 2007, 2015; Ribeiro et al., 2011). To specify with an example, a dyad may start a session with an exploratory intervention from the therapist how are you today?, followed by a client attributive statement I'm sad (depicted by a hollow circle in a cell that intersects therapist exploratory intervention and client attributive statement) and then, in the next turntaking, the therapist can use an action intervention let's talk about it. Responded by the client with an insight statement this feeling is so repetitive in my life (depicted by a full circle in a cell that intersects therapist action intervention and 
client insight statement, connected to the previous turntaking by a line).

The system can only be in a given state (cell) at a particular moment in time, even if other possibilities in the dyad were available (represented by other cells; Hollenstein, 2015). However, when a change occurs in dyadic behavior, a new circle appears in the cell, and a new line and arrow are drawn. This depicts a graphic movement, a pattern of dyadic interaction along the grid, providing information on the structural dynamics and temporal trajectory of the dyad, i.e. flexibility between cells (referring to movements across the cells, creating a trajectory that is more or less spread along the grid - evidencing more or less flexibility in the dyadic interaction) or attractors (a name for the cells that concentrate most of the interactions occurring in the dyad (Hollenstein, Granic, Stoolmiller, \& Snyder, 2004; Ribeiro et al., 2011).

Theoretically, all dynamic systems that are self-organized tend to stabilize in certain states, known as attractors. The attractors are a recurrent, redundant and stable intersection of dyadic behaviors that absorb and attract the system from other potential states (Hollenstein et al., 2004, p. 597). Attractors correspond to the cells with a higher frequency of occurrences (Tomicic et al., 2015). To make this concept clearer, Hollenstein and collaborators (2004) provide some examples that illustrated this pattern in a family dynamic: $a$ state of mutual hostility can be understood as an attractor for a particular family that means that they easily get drawn toward a hostile pattern of interaction and once the conflict has begun, it is difficult to pull out of this (p. 597). The process of change is evidenced when there is movement between and variability in different attractors over time (Hayes, Yasinski, Barnes, \& Bockting, 2015; Hollenstein, 2007; Howertwe, Hollenstein, Boon, Niemeyer, \& Brulee, 2012; Lewis et al., 1999, 2004; Ribeiro et al., 2011, for other studies using this type of analysis).

To verify which dyadic behaviors are considered as attractors of the system we used Marc Lewis' winnowing technique (Lewis et al., 1999), which consists of a series of runs in order to calculate the heterogeneity of each grid. At the beginning, we started with all cells visited (with circles) in the grid and shift, at each round, to a smaller set of cells (Tomicic et al., 2015). The mathematical process continues until we have a percentage of the heterogeneity of the grid lower than $50 \%$. For that, in each round we have to remove cell-by-cell, starting from the lowest frequencies and divide the heterogeneity score for each round by the heterogeneity grid score (Ribeiro et al., 2011). The following formula is used to measure the heterogeneity of each cell (Ribeiro et al., 2011, p. 63):

$$
\left.\mathrm{H}_{\mathrm{c}}=[(D / n)-d)\right]^{2} /(D / n)
$$

where $D$ corresponds to the total number of circles on the grid; $n$ is the number of cells with circles; $d$ corresponds to the number of circles in a specific cell. After that, it is necessary to calculate heterogeneity of the grid by the following formula:

$$
\mathrm{H}_{\mathrm{g}}=[n \Sigma(c) / n]
$$

where $n$ is the number of cells with circles and $c$ is the heterogeneity of each cell (obtained by the formula above) (Ribeiro et al., 2011).

On the other hand, measures such as flexibility also provide important information about the dyadic exchange. Flexibility is the system ability to adapt to changes that occur throughout the different dyadic behaviors (Hollenstein, 2007), in other words, the dispersion and transition of circles through the cells of the grid. According to Hollenstein and Lewis (2006), flexibility is the sum of the squared proportional durations across all cells, adjusted for the total number of cells in the grid matrix, and inverted so that values range from 0 (no dispersion: all behavior in one cell) to 1 (maximum dispersion: behavior equally distributed across the grid) (p. 659). There are no benchmarks in literature for assessing a good flexibility because this measure depends of the phenomenon under study. However, Hollenstein (2007) draws attention to some aspects that should be considered in the exploration of dyadic flexibility: i) the range or number of different behavioral states (p. 11), namely the number of cells with circles; ii) the number of transitions between those states (p. 11), namely the number of lines and arrows; and iii) the tendency to perseverate or get "stuck" in a small number of states (p. 11), namely very few variance in attractors. In this sense, a higher flexibility is associated with a higher dispersion and transitions within cells, and a lower flexibility is associated with a higher rigidity of dyadic behaviors (fewer cells). We choose here the dispersion measure since it has been considered a good indicator of flexibility (Oliveira, 2015). In Gridware, the following formula is used for its calculation:

$$
\left.\mathrm{D}_{\text {(dispersion) }}=1-\left[\left(n \Sigma\left(d_{i} / D\right) 2\right)-1\right) / n-1\right]
$$

where $n$ corresponds to the number of cells with circles; $d_{i}$ corresponds to the number of circles on a specific cell $(\mathrm{i}) ; D$ corresponds to the total number of circles on the grid (Hollenstein, 2007).

\section{Results}

\section{Evolution of immersion and distancing speech throughout the sessions}

In relation to the evolution of immersed and distanced speech, it is possible to observe, in Figure 1, that the immersed speech remains higher than the distanced speech until session 12, whereas in session 16 the distanced speech becomes predominant. 


\section{Evolution of therapist's interventions and client's speech}

As for the therapist's interventions (Figure 2), these have a stable evolution over time, with a predominance of exploration skills regarding other skills. However, insight and action skills slowly increase in session 1, 4 and
8. In terms of session 12, insight skills continue to increase and action skills start to decrease. Finally, in session 16, both skills decrease again.

Figure 3 shows the frequency of therapist's interventions that precede immersed and distanced speech. The analysis of this figure allows us to see that exploration

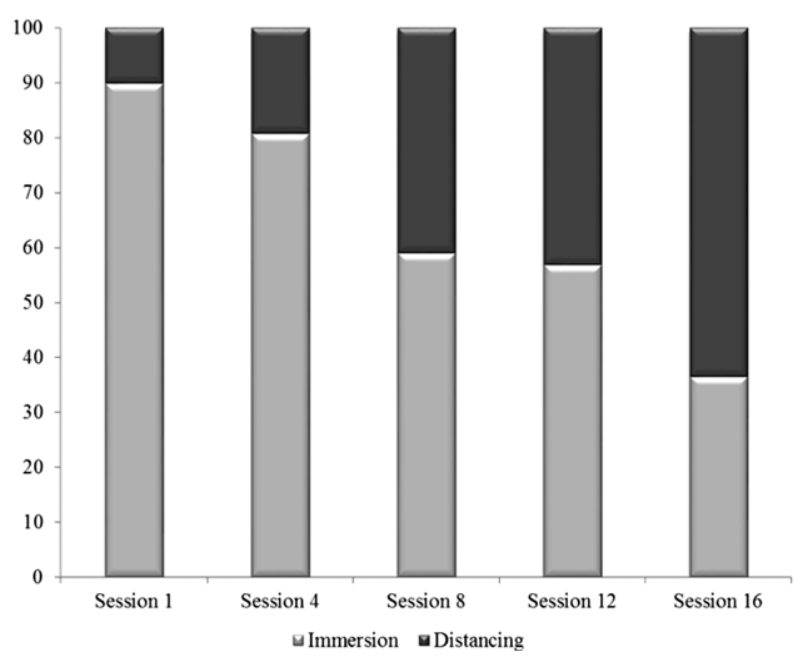

Figure 1. Absolute percentage of immersed and distanced speech.

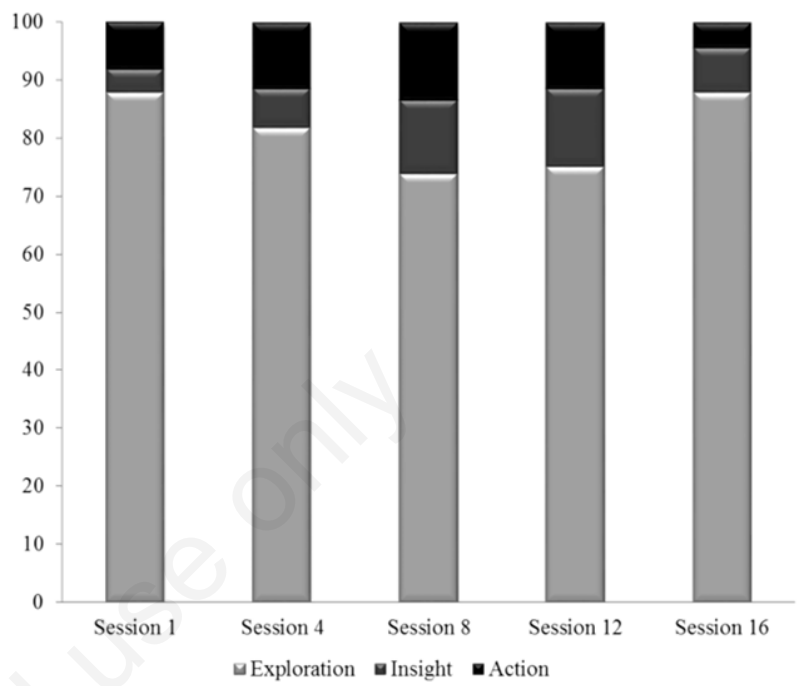

Figure 2. Absolute percentage of therapist's interventions.

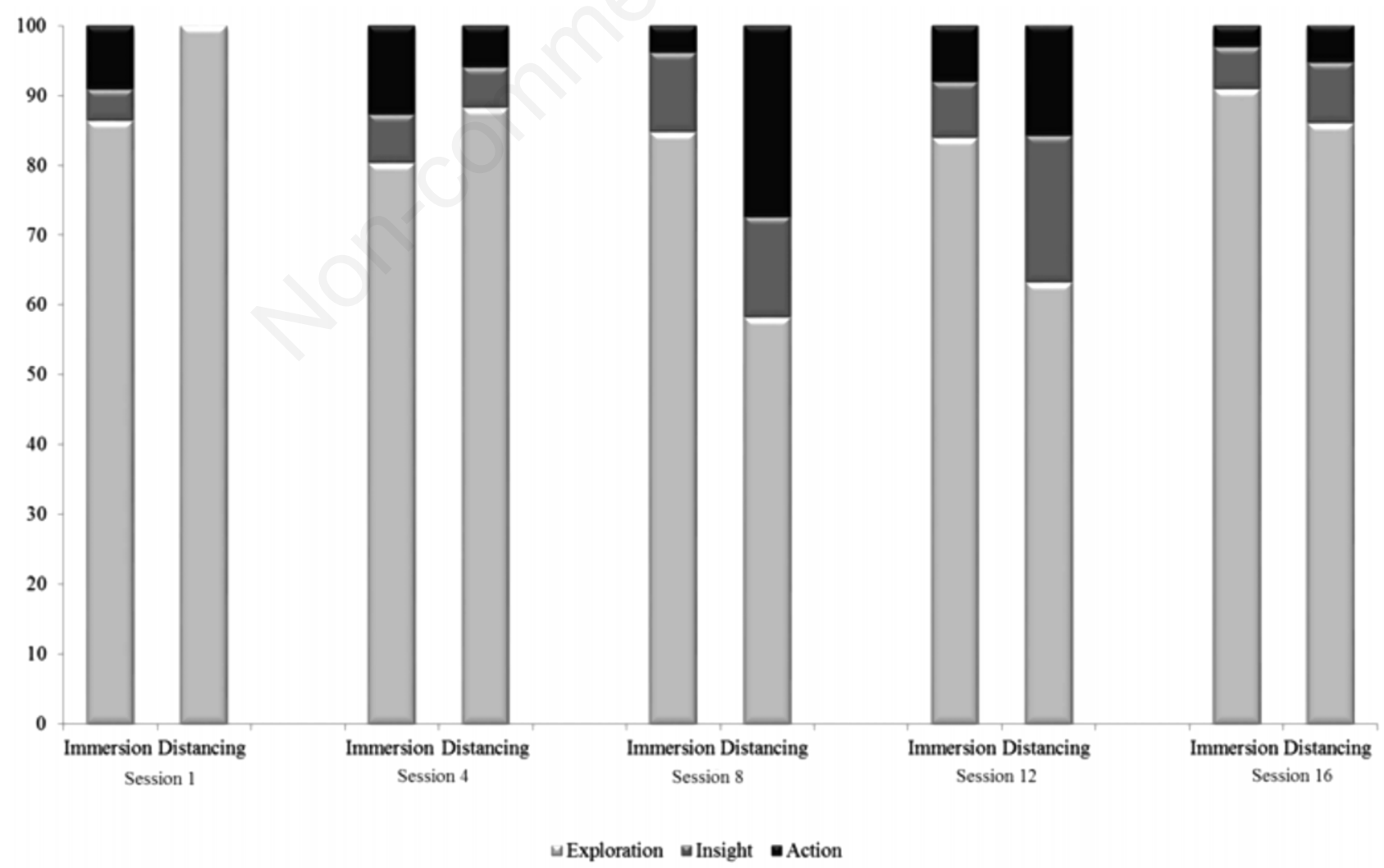

Figure 3. Percentage of immersed and distanced speech in therapist's interventions. 
skills are the intervention that more frequently precedes both speeches, in all five sessions analyzed. By contrast, insight and action skills precede both speeches at a lower frequency, with small differences between them. More specifically, exploration skills, for most of the sessions (except for session 1), precede immersed speech more frequently than distancing speech.

In terms of insight skills, session 1 is the only session that precedes immersed speech but not distancing speech. From session 4 to 8 there is an increase of insight skills preceding immersed speech, decreasing to session 12 and 16. By contrast, an increase of insight skills preceding distancing speech appears from session 1 to 12 , decreasing in session 16.

Finally, the frequency of action skills preceding immersed speech increases from session 1 to session 4 , decreasing to session 8 , increasing again to session 12 , and decreasing once again to session 16. However, the frequency of action skills preceding distancing speech increases from session 1 to 8 , and decrease to session 16 .

Overall, the exploration skills were the most frequent interventions that precede both client speeches (given that it was the most used by the therapist). However, it is not clear what happens in different phases of therapy. For this, we conducted a more intensive analysis of the different skills composing exploration interventions (Figure 4).

The results appearing in Figure 4 showed that open questions appear in session 1 as the most frequent therapist's skill preceding client's distancing speech (something that does occur in immersed speech). Approval was frequent in both speeches even though it occurred more in immersed than in distancing speech. It is important to point out that approval is a higher frequency intervention in immersed speech from session 8 to 16 , finalizing as the most frequent in both speeches. Finally, we found restatement and reflection of feelings in both immersed and distancing speech, but in different sessions. More specifically, we found restatement in session 1 for immersed speech and session 4 for distancing speech, and reflection of feelings in session 4 for immersed speech and session 12 for distancing speech.

\section{Dyadic patterns (client-therapist)}

The dyadic patterns according to the variables under study were analyzed using the Gridware and analysis of State Space Grids (Lamey et al., 2004), which illustrates which therapist interventions precede client immersed or distanced speech.

Figure 5 illustrates these patterns in sessions 1, 4, 8, 12 and 16, and its dispersion (equivalent to the dispersion of the circles in the cells) along the therapeutic process. The visual aspect of State Space Grids (Figure 5), which describes the evolution of the dyad, as well as shows the at-

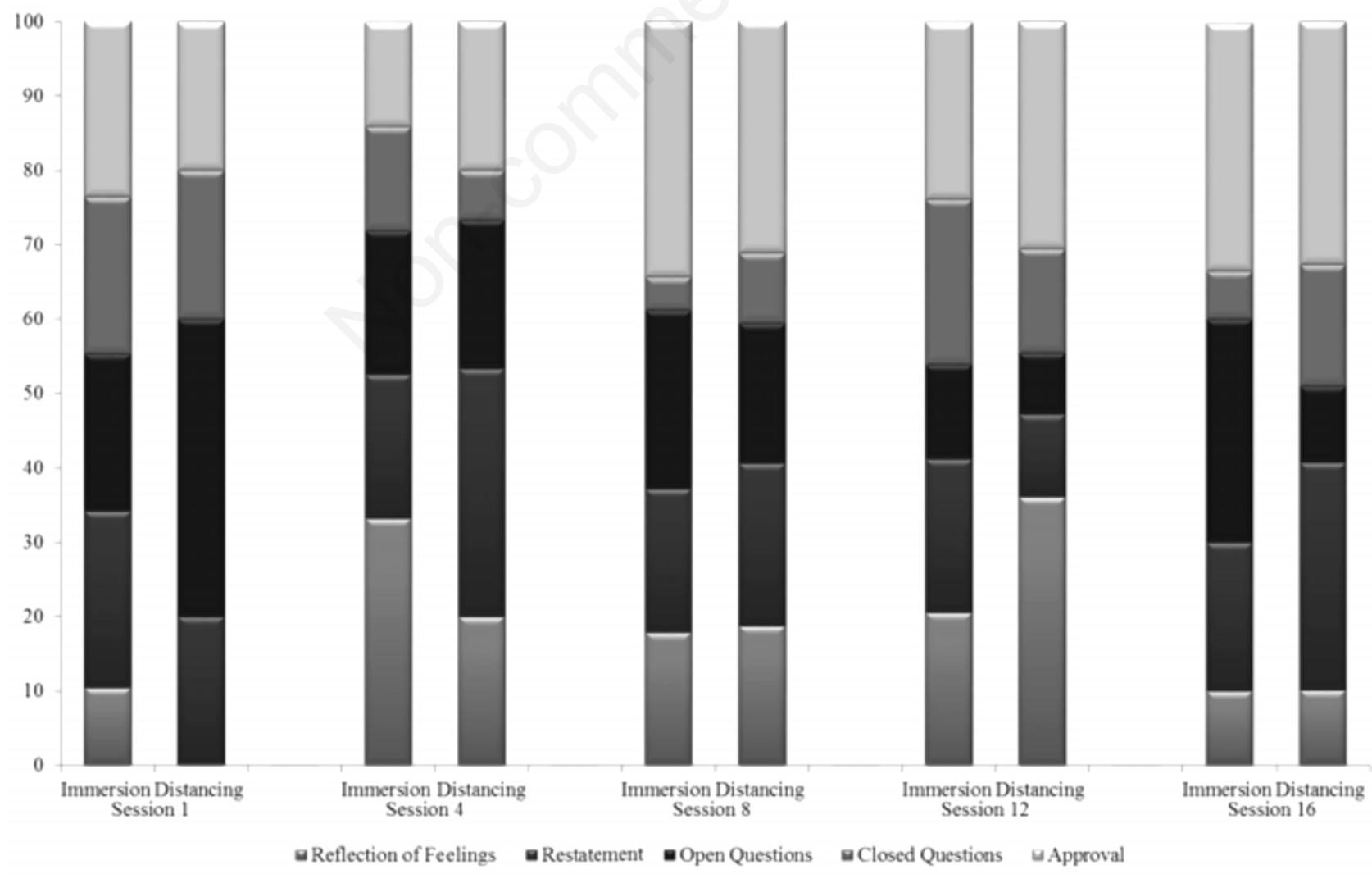

Figure 4. Percentage of immersed and distanced speech in exploration skills. 
tractors, is complemented by the values shown in Table 2, where it is possible to check the measure of flexibility of the dyadic behaviors in each session. The global flexibility increased from session 1 to 8 , stabilizing in session 12 , which shows a gradual expansion of therapist interventions and client speech. Then, in session 16 the global values of flexibility decrease. In terms of attractors (cells limited by black lines), it can be seen that behaviors were less dispersed in session 1 and 16 than in other sessions.

Observing each session individually, the attractors are distributed as follows: in session 1, the attractors were descriptive statements and attributive statements (client immersed speech) and exploration skills; in session 4, the

Table 2. Measures of flexibility of the dyad.

\begin{tabular}{lccccc}
\hline Measures & \multicolumn{5}{c}{ Sessions } \\
& $\mathbf{1}$ & $\mathbf{4}$ & $\mathbf{8}$ & $\mathbf{1 2}$ & $\mathbf{1 6}$ \\
\hline Flexibility & 0.742 & 0.82 & 0.865 & 0.865 & 0.854 \\
\hline
\end{tabular}

attractors were descriptive statements (immersed speech) with exploration and action skills, and also attributive statements (immersed speech) and insight statements (distanced speech) with exploration skills; in session 8, the attractors were exploration with both immersed and distanced speech and action skills with insight statements (distanced speech); in session 12, the attractors were exploration with both immersed and distanced speech and insight skills with insight statements (distanced speech), as well as action skills with attributive (immersed speech) and insight statements (distanced speech); finally, session 16 exhibited a retreat for exploration skills with all client speeches (immersed and distanced speech).

\section{Limitations and future directions}

One of the major limitations of this study is that it was focused on a single case, with only five sessions analyzed, which limited the quantitative analysis as well as the scope of the conclusions drawn from (i.e. these cannot be
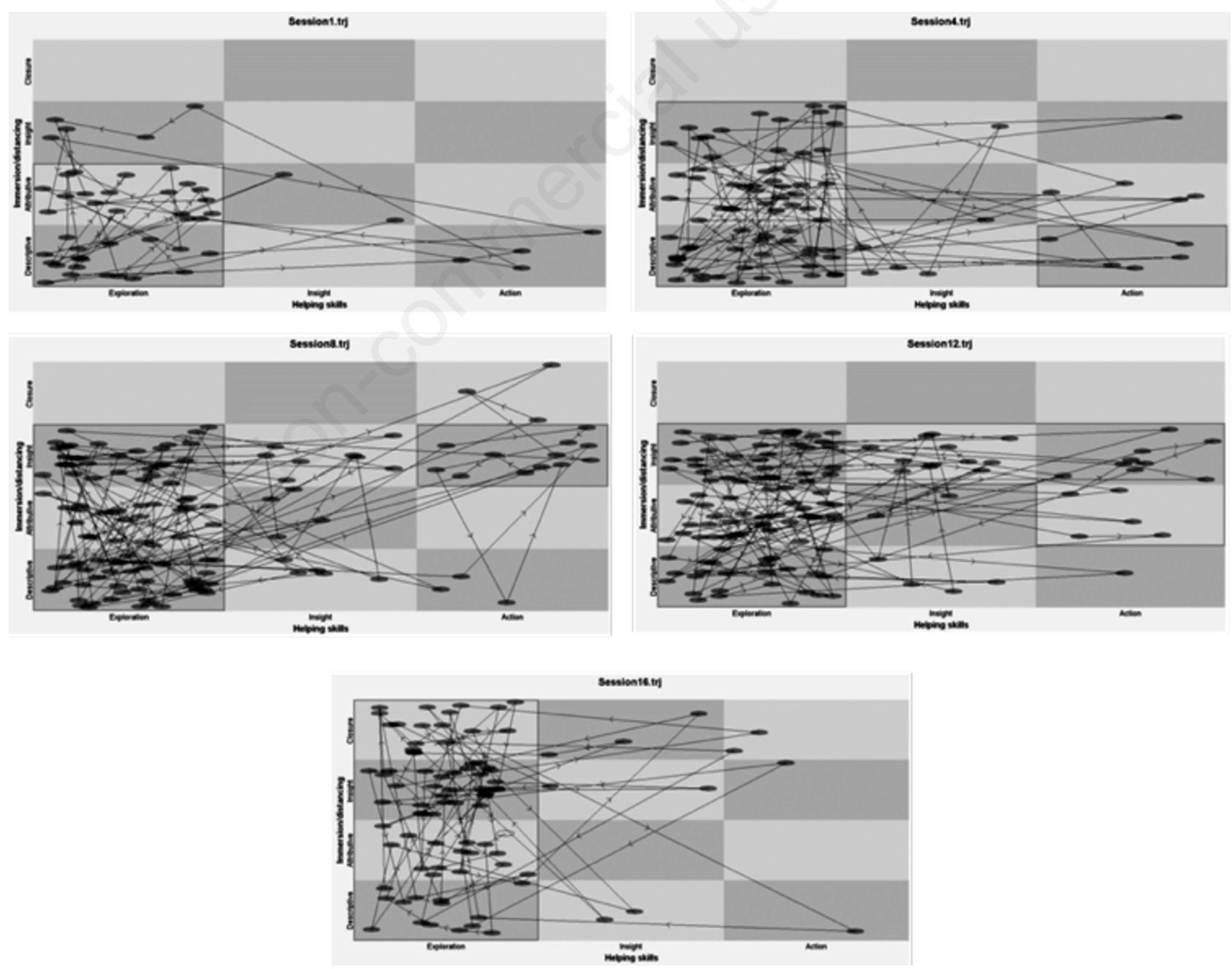

Figure 5. Dyadic patterns. 
generalized to other cases). However, we chose these sessions in order to converge our analysis with the sessions in which the depressive and general symptoms (BDI-II; OQ-45.2) were accessed throughout the process. In the future, other studies should be extended to more cases, with different outcomes, and also focus on other types of therapies, and other types of disorders (beyond depression), trying to analyze the evolution of the variables presented here in a broader sample

In our data analysis, the present study only looked to the relation between adjacent pairs' of interactions in the dyad (client and therapist) and respective categories, which is considered as the lag 1 association (Greenberg, 1986). Yet, this could not be sufficient to capture the antecedent processes $(\operatorname{lag}>1)$, which extend beyond the immediate outcomes and provide a longer impact of the therapist interventions in client speech (Elliott, 2010). However, Elliott, James, Reimschuessel, Cislo and Sack (1985) suggest that the study of immediate therapeutic impacts can still be useful to access the association between therapist and client processes (namely therapist interventions and client speech, in this case).

One of the main difficulties encountered during the development of this study was the fact that clinical studies on immersion and distancing are still very limited. The main findings are derived from laboratory experiments, with scarce applications to the field of clinical and psychotherapy research up until now (e.g. Barbosa, Bento, et al., 2012). This made the theoretical framing of the variables difficult yet, at the same time, this adds relevant and innovation to the present study.

Another difficulty was related to the use of the HSS, which is a transtheoretical model of therapist interventions. Like any other transtheoretical model, despite the advantage of providing a common lens for the comparison of different therapeutic modalities, it usually leads to some added difficulties when it is applied to a specific modality such as EFT. This difficulty here may have been aggravated as some of the judges did not have a significant, direct, clinical experience with the psychotherapy model in focus, at least when they were performing that stage of the analysis, even though they had previous theoretical training and observed the videotaped EFT sessions. Similarly to the distancing and immersed measure (MIDS), HSS only very recently it is being applied in clinical studies, namely, in experiential therapies (i.e. EFT).

\section{Discussion}

In this EFT case, the client progresses in the direction of a gradual decrease of immersed speech and an increase of distanced speech during the psychotherapy process. The turning point for the predominance of distanced speech is the last session (16), which is in line with previous investigations (Barbosa, Bento et al.,
2012; Barbosa et al., 2013; Barbosa, Salgado et al., 2012). These results suggest that, for the development of a good-outcome process, in the initial phase of EFT, it may be important for the client to be immersed. At least for this case, we argue that a higher immersed speech, at an initial stage, may facilitate a greater access of this client to her own experience, allowing new understandings, and even the resolution of relevant problems. The higher frequency of distanced speech in the last session is a finding also consistent with previous laboratory investigations (Ayduk \& Kross, 2010a, 2010b; Kross, 2009; Kross \& Ayduk, 2009, 2011; Kross et al., 2005), raising the hypothesis that the predominance of distanced speech in a final phase of therapy may also be an important step of a good-outcome process in an experiential therapy such as EFT.

In terms of specific therapist's interventions, in this case the client's immersed and distancing speeches were preceded by therapist's exploration skills such as restatements and reflection of feelings in an initial phase, and approval and reassurance in a final phase. These differences seem to occur in the middle phase (session 12), corresponding to a working-through phase of EFT, where therapist empathy leads to an increased awareness and arousal of client painful emotions (throughout approval). Also in this phase of EFT, through the use of therapist exploration skills like reflection of feelings, the therapist may have facilitated client's distanced speech during the process of reflecting and transforming emotional responses: for example, when the therapist followed client reflections about the way she felt before and the differences regarding the way she feels now (closure statement of distancing speech). The predominance of exploration skills in this case is consistent with previous studies on EFT that show a high prevalence of this type of therapist interventions, congruently to the development of goodoutcome process of EFT (Cunha et al., 2012; GoatesJones, 2004; Goates-Jones et al., 2009).

In terms of flexibility measures, the findings in this case point to a flexible style of interaction from both interlocutors of dyad (therapist and client), characterized with a higher frequency of therapist exploration interventions (although with some action skills in sessions 4, 8 and 12 and insight skills, in session 8). As for Julia, the client, she showed some flexibility, moving through the various speeches across sessions. This flexibility of the dyad added some dispersion, particularly from session 1 to 12 . We consider that these results are consistent with the EFT model, where a high flexibility in the therapeutic process needs to exist, as therapists try to work on the here and now, focusing on what is more poignant and more salient in what the client brings for that specific session (Elliott et al., 2004; Greenberg, 2010; Greenberg \& Watson, 2006; Pos \& Greenberg, 2007). In other words, in a working-through phase of EFT, therapists work with the experiences that clients provide to focus in the sessions 
(Greenberg \& Watson, 2006), which could lead to an increase of dispersion or diversity of behavior between therapist and client.

In addition, this case evidenced that attractors remain stable in terms of exploration skills between session 8 and 12 , even though in session 1 exploration skills were associated only with descriptive and attributive statements (immersed speech) and, in session 16, exploration skills were associated with all client speeches (immersed and distanced speech). These results are consistent with the specificities of EFT, due to a greater focus on client emotional experience which may led to a more detailed exploration in order to understand core, maladaptive emotional patterns (Greenberg \& Watson, 2006; Pos \& Greenberg, 2007). On the other hand, action skills appeared as attractors from session 4 to 12 , which is expected of EFT, once the therapist tries to facilitate specific tasks from the EFT model during this working-through, middle phase of the process (Pos \& Greenberg, 2007; Greenberg \& Watson, 2006).

\section{Conclusions}

To conclude, the results found in the present study, both at the level of speech evolution and the dyadic patterns can be related to the specificity of the therapy (EFT), namely: i) the focus on client's emotional experience, and ii) the detailed exploration of client's experience. This is a therapy that, at an initial stage, could lead therapists to drive clients to a more immersed speech in such a way as to be able to access, in a more detailed, profound manner, their own experience (Greenberg \& Watson, 2006; Pos \& Greenberg, 2007).

\section{References}

American Psychiatric Association (2006). DSM-IV-TR: manual de diagnóstico das perturbações mentais [DSM-IV-TR: diagnostic and statistical manual of mental disorders]. 4th ed. Washington, DC: American Psychiatric Association Publ.

Ayduk, Ö., \& Kross, E. (2010a). Analyzing negative experiences without ruminating: the role of self-distancing in enabling adaptive self-reflection. Social and Personality Psychology Compass, 4, 841-854. doi: 10.1111/j.1751-9004.2010.00301.x

Ayduk, Ö., \& Kross, E. (2010b). From a distance: implications of spontaneous self-distancing for adaptative self-reflection. Journal of Personality and Social Psychology, 98, 809-829. doi: 10.1037/a0019205

Barbosa, E., Bento, T., Amendoeira, M., Mendes, S., Gouveia, J., \& Salgado, J. (2012). Immersion, distancing and emotional arousal: an intensive case study of a good outcome case of CBT. Paper presented at the 3th Conference of Society for Psychotherapy Re-search European and UK Chapters, Porto, Portugal.

Barbosa, E., Lourenço, P., Amendoeira, M., Gouveia, J., \& Salgado, J. (2013). Inmersión, distanciamiento y activación emocional en casos de éxito de terapia focalizada en la eción y terapia cognitivo-conductual. [Immersion, distancing and emotional arousal in cases of cognitive-beahvioral therapy]. Paper presented at the 6th International Congress of Clinic Psychology, Santiago de Compostela, Spain.

Barbosa, E., Salgado, J., Ferreira, T., Lourenço, P., Pinto, P. (2012). Immersion, distancing and emotional arousal: an intensive case study of a good outcome case of EFT. Paper presented at the 43th International Conference of Society for Psychotherapy Research, Virginia Beach, VA, USA.

Bickman, L. (2008). A measurement feedback system (MFS) is necessary to improve mental health outcomes. Journal of American Academy of Child and Adolescent Psychiatry, 47, 1114-1119. doi: 10.1097/CHI.0b013e3181825af8

Bucci, W. (2013). The referential process as a common factor across treatment modalities. Research in Psychotherapy: Psychopathology, Process and Outcome, 16, 16-23. doi: 10.7411/ RP.2013.003

Chui, H., Hill, C., Ain, S., Ericson, S., Del Pino, H., Hummel, A., Spangler, P. (2014). Training undergraduate students to use challenges. The Counseling Psychologist, 42, 758-777. doi 10.1177/0011000014542599

Coelho, R., Martins, A., Barros, H. (2002). Clinical profiles relating gender and depressive symptoms among adolescents ascertained by the Beck Depression Inventory II. European Psychiatry, 17, 222-226. doi: 10.1016/S0924-9338(02)00663-6

Cunha, C., Gonçalves, M., Hill, C., Mendes, I., Ribeiro, A., Sousa, A., ..., Greenberg, L. (2012). Therapist interventions and client innovative moments in emotion-focused therapy for depression. Psychotherapy: Theory, Research, Practice, Training, 49, 536-548. doi: 10.1037/a0028259

Dagnino, P., Krause, M., Pérez, C., Valdés, N., \& Tomicic, A. (2012). The evolution of communicative intentions during change episodes and throughout the therapeutic process. Research in Psychotherapy: Psychopathology, Process and Outcome, 15, 75-86. doi: 10.7411/RP.2012.008

Elliott, R. (2010). Psychotherapy change process research: realizing the promise. Psychotherapy Research, 20, 123-135. doi: 10.1080/10503300903470743

Elliott, R., James, E., Reimschuessel, C., Cislo, D., \& Sack, N. (1985). Significant events and the analysis of immediate therapeutic impacts. Psychotherapy, 2, 620-630. doi: 10 . 1037/h0085548

Elliott, R., Watson, J., Goldman, R., \& Greenberg, L. (2004). Learning emotion focused therapy. Washington, DC: American Psychiatric Association Publ.

First, M., Gibbon, M., Williams, J., \& Benjamin, L. (1997). Structured clinical interview for DSM-IV Axis II personality disorders (SCID-II). Washington, DC: American Psychiatric Association Publ.

First, M., Spitzer, R., Gibbon, M., \& Williams, J. (1997). Structured clinical interview for DSM-IV Axis I personality disorders (SCID-I). Washington, DC: American Psychiatric Association Publ.

Gendlin, E. (1996). Focusing oriented psychotherapy. New York, NY: Guildford.

Goates-Jones, M. (2004). Psychotherapy process in the exploration stage. Washington, DC: Faculty of the Graduate School of the University of Maryland.

Goates-Jones, M., Hill, C., Stahl, J., \& Doscheck, E. (2009). Therapist response modes in the exploration stage: timing and effectiveness. Counselling Psychology Quarterly, 22, 221-231. doi: 10.1080/09515070903185256

Granic, I. \& Hollenstein, T.P. (2003). Dynamic systems methods 
for models of developmental psychopathology. Development and Psychopathology, 15, 641-669. doi: 10.1017/S095 4579403000324

Greenberg, L.S. (1986). Change process research. Journal of Consulting and Clinical Psychology, 54, 4-9. doi: 10.1037/ 0022-006X.54.1.4

Greenberg, L.S. (2002). Emotion-focused therapy: coaching clients to work through their feelings. Washington, DC: American Psychiatric Association.

Greenberg, L.S. (2006). Emotion focused therapy: a synopsis. Journal of Contemporary Psychotherapy, 36, 86-93. doi: 10.1007/s10879-006-9011-3

Greenberg, L.S. (2010). Emotion-focused therapy: an overview. Turkish Psychological Counseling and Guidance Journal, 4,1-12. doi: 1058000242/1058000244

Greenberg, L., \& Pacoal-Leone, A. (2006). Emotion in psychotherapy: a practice-friendly research review. Journal Clinical Psychology, 62, 611-630. doi:10.1002/jclp.20252

Greenberg, L., Rice, L. \& Elliott, R. (1993). The moment by moment process: facilitating emotional change. New York, NY: Guilford Press.

Greenberg, L., \& Watson, J. (2006). Emotion-focused therapy for depression. Washington, DC: American Psychiatric Association.

Hayes, A., Yasinski, C., Barnes J.B., \& Bockting, C. (2015). Network destabilization and transition in depression: new methods for studying the dynamics of therapeutic change. Clinical Psychology Review, 41, 27-39. doi: 10.1016/j.cpr. 2015.06.007

Hess, S., Knox, S., \& Hill, C.E. (2006). Teaching graduate student trainees how to manage client anger: a comparison of three types of training. Psychotherapy Research, 16, 282292. doi: $10.1080 / 10503300500264838$

Hill, C.E. (1978). Development of a counselor verbal category system. Journal of Counseling Psychology, 25, 461-468. doi: 10.1037/0022-0167.25.5.461

Hill, C. (2002). Development and use of the helping skills measure to assess client perceptions of the effects of training and of helping skills in sessions. Journal of Counseling Psychology, 49, 164-172. doi: 10.1037//0022-0167.49.2.264

Hill, C. (2004). Helping skills: facilitating exploration, insight, and action. 3rd ed. Washington, DC: American Psychiatric Association.

Hill, C. (2005). Therapist techniques, client involvement, and the therapeutic relationship: inextricably intertwined in the therapy process. Psychotherapy: Theory, Research, Practice, Training, 42, 431-442. doi: 10.1037/0033-3204.42.4.431

Hill, C. (2014). Helping skills: facilitating exploration, insight, and action. 4th ed. Washington, DC: American Psychiatric Association.

Hill, C., Baumann, E., Shafran, N., Gupta, S., Morrison, A., Rojas, A., Gelso, C. (2015). Is training effective? A study of counseling psychology doctoral trainees in a psychodynamic/interpersonal training clinic. Journal of Counseling Psychology, 62, 184-201. doi.org/10.1037/cou0000053

Hill, C., \& Lambert, M. (2004). Methodological issues in studying psychotherapy processes and outcomes. In: M.J. Lambert (Ed.), Bergin and Garfield's handbook of psychotherapy and behavior change (5th ed., pp. 84-135). New York, NY: John Wiley \& Sons.

Hill, C., Spangler, P., Chui, H., \& Jackson, J. (2014). Training undergraduate students to use insight skills: overview of the rationale, methods, and analyses for three studies. The Coun- seling Psychologist, 42, 702-728. doi: 10.1177/00110000 14542598

Hill, C., Spangler, P., Jackson, J., \& Chui, H. (2014). Training undergraduate students to use insight skills: integrating the results of three studies. The Counseling Psychologist, 42:800-820. doi: 10.1177/0011000014542602

Hollenstein, T. (2007). State space grids: analyzing dynamics across development. International Journal of Behavioral Development, 31, 384-396. doi: 10.1177/0165025407077765

Hollenstein, T. (2015). The dynamic systems perspective: what is the system? In: L.C. Mayes \& M. Lewis (Eds.), The Cambridge handbook of environment in human development (pp. 138-151). New York, NY: Cambridge University Press.

Hollenstein, T., Granic, I., Stoolmiller, M., \& Snyder, J. (2004). Rigidity in parent-child interactions and the development of externalizing and internalizing behavior in early childhood. Journal of Abnormal Child Psychology, 32, 595-607. doi: 10.1023\%2FB\%3AJACP.0000047209.37650.41

Hollenstein, T., \& Lewis, M.D. (2006). A state space analysis of emotion and flexibility in parent-child interactions. Emotion, 6, 663-669. doi: 10.1037/1528-3542.6.4.656

Howertwe, A., Hollenstein, T., Boon, H., Niemeyer, K., \& Brule, D. (2012). State-space grid analysis: applications for clinical whole systems complementary and alternative medicine research. Forsch Komplementmed, 19, 30-35. doi: 10.1159/ 000335187

Jackson, J., Hill, H., Spangler, P., Ericson, S., Merson E., Liu, J., .., Reen, G. (2014). Training undergraduate students to use interpretation. The Counseling Psychologist, 42, 778799. doi: $10.1177 / 0011000014542600$

Jacobson, N., \& Truax, P. (1991). Clinical significance: a statistical approach to defining meaningful change in psychotherapy research. Journal of Consulting and Clinical Psychology, 59, 12-19. doi: 10.1037/0022-006X.59.1.12

Kross, E. (2009). When the self becomes other: toward an integrative understanding of the processes distinguishing adaptive self-reflection from rumination. Values, Empathy, and Fairness across Social Barriers: Annals of the New York Academy of Sciences, 1167, 35-40. doi: 10.1111/j.17496632.2009.04545.x

Kross, E., \& Ayduk, Ö. (2008). Facilitating adaptive emotional analysis: distinguishing distanced-analysis of depressive experiences from immersed-analysis and distraction. Personality and Social Psychology Bulletin, 34, 924-938. doi: 10.1177/0146167208315938

Kross, E., \& Ayduk, Ö. (2009). Boundary conditions and buffering effects: does depressive symptomology moderate the effectiveness of self-distancing for facilitating adaptive emotional analysis? Journal of Research in Personality, 43, 923-927. doi: 10.1016/j.jrp.2009.04.004

Kross, E., \& Ayduk, Ö. (2011). Making meaning out of negative experiences by self-distancing. Current Directions in Psychological Science, 20, 187-191. doi: 10.1177/0963721411 408883

Kross, E., Ayduk, Ö., \& Mischel, W. (2005). When asking "why" does not hurt: distinguishing rumination from reflective processing of negative emotions. Psychological Science, 16, 709-715. doi: 10.1111/j.1467-9280.2005.01600.x

Lambert, M. (2012). The outcome questionnaire-45. Integrating Science and Practice, 2, 24-27.

Lamey, A., Hollenstein, T., Lewis, M., \& Granic, I. (2004). GridWare (version 1.1). [Computer software]. Retrieved from: http://statespacegrids.org 
Lewis, M., Lamey, A., \& Douglas, L. (1999). A new dynamic systems method for the analysis of early socioemotional development. Developmental Science, 2, 458-476. doi: 10.1111/ 1467-7687.00090

Lewis, M., Zimmerman, S., Hollenstein, T., \& Lamey, A. (2004). Reorganization in coping behavior at $1 \frac{1}{2}$ years: dynamic systems and normative change. Developmental Science, 7, 56-73. doi: 10.1111/j.1467-7687.2004.00323.x

Machado, P., \& Fassnacht, D. (2014). The Portuguese version of the outcome questionnaire (OQ-45): normative data, reliability, and clinical significance cut-offs scores. Psychology and Psychotherapy: Theory, Research and Practice, 88, 427-437. doi:10.1111/papt.12048

McGlinchey, J.B., Atkins, D.C., \& Jacobson, N.S. (2002). Clinical significance methods: which one to use and how useful are they? Behavior Therapy, 33, 529-550. doi: 10.1016/ S0005-7894(02)80015-6

Mergenthaler, E., \& Stinson, C. (1992). Psychotherapy transcription standards. Psychotherapy Research, 2, 125-142. doi: 10.1080/10503309212331332904

Meystre, C., Pascual-Leone, A., Roten, Y., Despland, J.N., \& Kramer, U. (2014). What interventions facilitate client progress through the assimilation model? A task analysis of interventions in the psychodynamic treatment of depression. Psychotherapy Research, 25, 484-502. doi: 10.1080/1050 3307.2014 .921352

Nigro, G., \& Neisser, U. (1983). Point of view in personal memories. Cognitive Psychology, 15, 467-482. doi:10.1016/0010 -0285(83)90016-6

Nolen-Hoeksema, S. (1991). Responses to depression and their effects on the duration of depressive episodes. Journal of Abnormal Psychology, 100, 569-82. doi: 10.1037/0021843X.100.4.569

Nuovo, S. (2011). Speaking about therapists... Old questions and some answers derived from empirical evidence. Research in Psychotherapy: Psychopathology, Process and Outcome, 14, 52-75. doi: 10.4081/ripppo.2011.22

Oliveira, D. (2015). Momentos de inovação: emergência e evolução das protonarrativas em terapia narrativa [Innovation moments: emergency and evolution of protonarrative in narrative therapy]. Braga: Universidade de Minho Publ.

Pos, A.E., \& Greenberg, L.S. (2007). Emotion-focused therapy: the transforming power of affect. Journal of Contemporary Psychotherapy, 37, 25-31. doi: 10.1007/s10879-006-9031-z
Provenzi, L., Borgatti, R., Menozzi, G., \& Montirosso, R. (2015). A dynamic system analysis of dyadic flexibility and stability across the face-to-face still-face procedure: application of the State Space Grid. Infant Behavior and Development, 38, 1-10. doi: 10.1016/j.infbeh.2014.10.001

Ribeiro, A., Bento, T., Salgado, J., Stiles, W., \& Gonçalves, M. (2011). A dynamic look at narrative change in psychotherapy: a case study tracking innovative moments and protonarratives using state space grids. Psychotherapy Research, 21, 54-69. doi: 10.1080/10503307.2010.504241

Salvatore, S., \& Tschacher, W. (2012). Time dependency of psychotherapeutic exchanges: the contribution of the theory of dynamic systems in analyzing process. Frontiers in Psychology, 3, 1-14. doi: 10.3389/fpsyg.2012.00253

Seggar, L.B., Lambert, M.J., \& Hansen, N.B. (2002). Assessing clinical significance: application to the Beck Depression Inventory. Behavior Therapy, 33, 253-269. doi:10.1016/ S0005-7894(02)80028-4

Spangler, P., Hill, C., Dunn, M., Hummel, A., Walden, T., Liu, J., ..., Salahuddin, N. (2014). Training undergraduate students to use immediacy. The Counseling Psychologist, 42, 729-757. doi: 10.1177/0011000014542835

Steer, R., Ball, R., Ranieri, W., \& Beck, A., (1999). Dimension of Beck Depression-II in clinical depressed outpatients. Journal of clinical Psychology, 55, 117-128. doi: 10.1002/(SICI)10974679(199901)55:1<117::AID-JCLP12>3.0.CO;2-A

Steer, R.A., Brown, G.K., Beck, A.T., \& Sanderson, W.C. (2001). Mean Beck Depression Inventory-II scores by severity of major depressive episode. Psychological Reports, 88, 1075-1076. doi: 10.2466/pr0.2001.88.3c.1075

Tomicic, A., Martínez, C., Pérez, J., Hollenstein, T., Angulo, S., Gerstmann, A., ..., Krause, M. (2015). Discourse-voice regulatory strategies in the psychotherapeutic interaction: a state-space dynamics analysis. Frontiers in Psychology, 6, 1-17. doi:10.3389/fpsyg.2015.00378

Town, J., Hardy, G., Mccullough, L., \& Stride, C. (2012). Patient affect experiencing following therapist interventions in short-term dynamic psychotherapy. Psychotherapy Research, 22, 208-219. doi: 10.1080/10503307.2011.637243

Trop, J., Burke, M., \& Trop, G. (2013). Psychoanalytic theory and psychotherapy: a dynamic systems view of change. Clinical Social work Journal, 41, 34-42. doi: 10.1007\% 2Fs10615-012-0403-4 